\title{
PVD thermal barrier coating systems for Mo-Si-B alloys
}

\author{
A. Lange*, R. Braun, U. Schulz
}

German Aerospace Center (DLR), Institute of Materials Research, D-51170 Köln, Germany *now with Schott AG, D-55122 Mainz, Germany

\begin{abstract}
Mo-Si-B alloys possessing melting points exceeding $2000^{\circ} \mathrm{C}$ are promising candidates for high temperature structural applications outperforming the service temperatures of the currently employed Ni-based superalloys. However, their oxidation behaviour is poor, in particular at temperatures below $1000^{\circ} \mathrm{C}$, suffering from evaporation of $\mathrm{MoO}_{3}$. Application of protective coatings forming continuous silica/borosilicate scales is a viable approach to enhance the oxidation resistance. In the combustion environments of gas turbines, however, the oxide scales require environmental protection by ceramic topcoats which can moreover operate as thermal barrier coatings (TBCs). In the present feasibility study, Mo-9Si-8B (at.\%) specimens were coated with different $5-10 \mu \mathrm{m}$ thick oxidation protective layers produced by magnetron sputtering. Their chemical compositions in at.\% were Mo-70Al, Mo-46Si-24B, Mo-37Si-15B and Mo-47Si-24Al. On the pre-oxidised coated samples, ceramic topcoats of 7 wt.\% yttria partially stabilized zirconia (YSZ) and gadolinium zirconate (GZO) were applied using electron-beam physical vapour deposition. The thickness of the TBCs was in the range between 145 and $160 \mu \mathrm{m}$. The specimens with the different TBC systems were exposed to air at $1000^{\circ} \mathrm{C}$ for periods between 20 and $100 \mathrm{~h}$. Post-oxidation cross-sectional analyses were carried out to study microstructural characteristics of the coated specimens.
\end{abstract}


Both as-deposited YSZ and GZO topcoats exhibited good adhesion to the pre-oxidised bond coats. After $20 \mathrm{~h}$ of exposure to air at $1000^{\circ} \mathrm{C}$, the Mo-70Al bond coat was entirely degraded in the region near the suspension hole related to oxidation of uncoated substrate material. In contrast, the YSZ topcoat was tightly-adherent to the borosilicate scale grown on the Mo46Si-24B bond coat. Similar results were obtained for GZO topcoats deposited on Mo-46Si24B and Mo-37Si-15B bond coats. The TBC system consisting of GZO topcoat and Mo-47Si$24 \mathrm{Al}$ bond coat, which formed a mixed scale of silica and mullite-like oxides, survived $100 \mathrm{~h}$ at $1000^{\circ} \mathrm{C}$. However, after this exposure time, the bond coats were approaching their lifetime due to the low layer thickness. Oxidation of the Mo-Si-B substrate occurring at unprotected areas around the suspension hole of the sample caused substantial degradation of the outer region of the GZO topcoat due to chemical reaction between $\mathrm{MoO}_{3}$ and $\mathrm{Gd}_{2} \mathrm{Zr}_{2} \mathrm{O}_{7}$. This corrosion attack led to complete destruction of the TBC systems after $10 \mathrm{~h}$ of exposure at $1300^{\circ} \mathrm{C}$.

Keywords: Mo-Si-B alloys, bond coats, thermal barrier coatings, yttria partially stabilised zirconia, gadolinium zirconate, 


\section{INTRODUCTION}

Refractory metal composites are considered as candidates for ultrahigh temperature applications in gas-turbine engines outperforming the service temperatures of the currently used Ni-based superalloys [1-3]. These Mo- and Nb-based materials possess multiphase microstructures containing a metallic solid solution and one or more intermetallics, predominantly silicides, to achieve balanced properties required for structural applications [4,5]. A weakness of these composites is the poor oxidation resistance of the metallic constituent forming non-protective oxides $[1,4,6]$. To improve their oxidation resistance without decline of mechanical properties, environmental protective coatings are likely to be applied $[7,8]$.

Mo-Si-B alloys are recently a focus of research and development [3,9-11]. These alloys with a typical chemical composition of Mo-9Si-8B (in at.\%) exhibit a three-phase microstructure consisting of $\alpha$-Mo solid solution $\left(\mathrm{Mo}_{\mathrm{ss}}\right)$ and the two Mo-silicides $\mathrm{Mo}_{3} \mathrm{Si}(\mathrm{A} 15)$ and $\mathrm{Mo}_{5} \mathrm{SiB}_{2}$ (called T2). With melting points around $2000^{\circ} \mathrm{C}$, they possess high strength and excellent creep resistance at elevated temperatures [3,8-11]. Their oxidation behaviour is characterised by the pesting phenomenon, a rapid destructive oxidation leading to disintegration of the material, at intermediate temperatures (around $700^{\circ} \mathrm{C}$ ) and by an initial mass loss followed by a state with considerably reduced mass change at temperatures above $1000^{\circ} \mathrm{C}[4,12]$. For MoSi-B alloys, oxidation resistant coatings have been developed which rely on the formation of protective borosilicate or alumina scales [7,13]. These coatings were produced by pack cementation or magnetron sputtering [14-17]. Generally, they comprised a diffusion barrier layer to hamper silicon and aluminium diffusion into the substrate, and an outer layer forming silica/borosilicate or alumina scales. The diffusion barrier consisted of the $\mathrm{Mo}_{5} \mathrm{SiB}_{2}$ phase, which exhibits a low silicon diffusion coefficient, and/or the MoB phase [7,18]. Outer $\mathrm{MoSi}_{2}$ and $\mathrm{Al}_{8} \mathrm{Mo}_{3}$ oxidation protective layers were applied. The $\mathrm{MoSi}_{2}$ phase as well as the $\mathrm{Mo}_{5} \mathrm{Si}_{3}$ 
phase, to which $\mathrm{MoSi}_{2}$ transforms due to depletion of Si consumed by silica formation and diffusion into the substrate, have to be saturated with boron. Boron supplied by the $\mathrm{Mo}_{5} \mathrm{SiB}_{2}$ and $\mathrm{MoB}$ phases accelerates the formation of a continuous borosilicate scale by reducing the viscosity of slowly growing silica layers and was found to prevent pesting oxidation of both molybdenum silicides [19,20].

For exposure at temperatures above $1200^{\circ} \mathrm{C}$, silica is the most appropriate protective scale because its growth rate at those temperatures is lower than that of alumina [21]. However, in gas turbine combustion environments, silica is not stable due to water vapour corrosion [22]. Therefore, environmental barrier coatings (EBCs) are required to prevent degradation of silica associated with the formation of volatile $\mathrm{Si}(\mathrm{OH})_{4}$, similarly to environmental protection of Sibased ceramics such as $\mathrm{SiC} / \mathrm{SiC}$ composites or $\mathrm{Si}_{3} \mathrm{~N}_{4}$. For the latter potential ultra-high temperature materials, extensive studies were performed to develop effective environmental barrier coatings, including rare earth silicates, mullite and barium strontium aluminosilicate (BSAS) $[23,24]$. Yttria partially stabilised zirconia (YSZ) is also considered to possess durability in water vapour containing environment as evidenced by its successful application on components in gas turbine environments $[22,23]$. YSZ is the standard material for thermal barrier coatings (TBCs) on gas turbine components to increase their operating temperature and/or their lifetime $[25,26]$. The service temperatures of $\mathrm{YSZ}$ are limited to about $1200^{\circ} \mathrm{C}$ due to phase stability and sintering effect [27]. For higher temperatures, TBCs of gadolinium zirconate $\left(\mathrm{Gd}_{2} \mathrm{Zr}_{2} \mathrm{O}_{7}, \mathrm{GZO}\right)$ were developed exhibiting a pyrochlore structure stable up to $1500^{\circ} \mathrm{C}$ [28]. Both YSZ and GZO TBCs have been applied on Ni-based superalloys with alumina forming bond coats. For GZO topcoat, however, $\mathrm{Gd}_{2} \mathrm{Zr}_{2} \mathrm{O}_{7}$ was found to be incompatible with alumina forming $\mathrm{GdAlO}_{3}$ [29]. Therefore, for long-term exposure an intermediate YSZ layer is probably required to prevent chemical reactions between GZO and the thermally grown oxide (TGO) [30]. 
The oxidation protective layers on Mo-Si-B alloys are predominantly silica/borosilicate formers. Studies on environmental/thermal barrier coatings with silica forming bond coats are scarce. Excellent performance was observed for YSZ TBCs on Nb-silicide composites with a silicide bond coat which were subjected to furnace cycling and jet-engine thermal simulation testing up to $1370^{\circ} \mathrm{C}$ and $1650^{\circ} \mathrm{C}$, respectively [5]. YSZ and GZO topcoats were also applied on $\mathrm{Nb} / \mathrm{Nb}_{5} \mathrm{Si}_{3}$-based alloys with complex silicide coatings forming chromia/silica scales. Lifetimes up to 1000 cycles (60/10 minutes at high/ambient temperatures) were obtained for these E/TBC systems from furnace cycling tests [31,32]. For Mo-Si-B alloys, only one study on thermal barrier coatings has been published in the literature $[33,34]$. In the latter work, a multi-layer architecture was proposed with mullite TBC and BSAS EBC on top. As precursor material for the formation of compositionally graded mullite, Al-Si coatings were investigated being adhesive and compatible with the Mo-Si-B substrate.

In the present study, TBC systems with YSZ and GZO topcoats were applied on Mo-9Si-8B substrate materials. Oxidation protective coatings forming scales of aluminium borate, borosilicate and a mixture of silica and mullite-like oxides were used as bond coats produced by magnetron sputtering. The potential of those TBC systems was studied by cross-sectional examinations after short-term exposure at $1000^{\circ} \mathrm{C}$ in air.

\section{EXPERIMENTAL}

The substrate material used were mechanically alloyed and sintered rods with the nominal composition Mo-9Si-8B (in at.\%) supplied by Plansee SE, Reutte, Austria. Flat rectangular specimens with $15 \times 10 \mathrm{~mm}^{2}$ in size were machined by spark erosion. The thickness was 1 or 2 $\mathrm{mm}$; and the surfaces were ground to a 2500-grit surface finish. The samples had a $1 \mathrm{~mm}$ 
diameter hole near the rim for handling during the coating deposition. On these coupons, four different bond coats were deposited using magnetron sputtering. Their chemical compositions in at.\% were Mo-70Al, Mo-46Si-24B, Mo-37Si-15B and Mo-47Si-24Al (in at.\%). The $5-10$ $\mu \mathrm{m}$ thick as-sputtered coatings were amorphous and, therefore, they were annealed in vacuum at $725^{\circ} \mathrm{C}(\mathrm{Mo}-70 \mathrm{Al})$ and $900^{\circ} \mathrm{C}$ (other coatings) to achieve crystalline structures. Some of the specimens had a $2 \mu \mathrm{m}$ thick intermediate diffusion barrier layer of the $\mathrm{Mo}_{5} \mathrm{SiB}_{2}$ (T2) phase (between substrate and bond coat) also produced by magnetron sputtering and annealing treatment. Details of the manufacture of the diffusion barrier and the bond coats are described elsewhere $[16,17,35]$. After annealing the coupons with bond coats were pre-oxidised in air at $800^{\circ} \mathrm{C}$ for $20 \mathrm{~h}$ to form a thin oxide scale to furnish adhesion of the TBC.

On the pre-oxidised coated samples, ceramic topcoats of $7 \mathrm{wt} . \%$ yttria partially stabilized zirconia and gadolinium zirconate were applied using electron-beam physical vapour deposition (EB-PVD). The thickness of the TBCs was in the range between 145 and $160 \mu \mathrm{m}$. The specimens with GZO topcoat had an intermediate T2 barrier layer to impede degradation of the bond coat by interdiffusion. The different $\mathrm{TBC}$ systems were exposed to air at $1000^{\circ} \mathrm{C}$ for periods between 20 and $100 \mathrm{~h}$ and at $1300^{\circ} \mathrm{C}$ for $10 \mathrm{~h}$. When tested at $1000^{\circ} \mathrm{C}$, the samples were removed from the furnace after $20 \mathrm{~h}$, visually inspected and thereafter, if considered intact, put into the furnace for a further high temperature exposure of $20 \mathrm{~h}$ dwell time. The TBC systems studied are compiled in Table 1 containing the chemical composition of the bond coats, their phases after vacuum annealing identified by X-ray diffraction, the application of a diffusion barrier as well as the oxidation testing parameters. Post-oxidation cross-sectional analyses were carried out using scanning electron microscopy (SEM) and energy-dispersive X-ray spectroscopy (EDS). 


\section{RESULTS AND DISCUSSION}

\subsection{YSZ topcoat}

Figure 1 shows a Mo-9Si-8B sample with Mo-70Al bond coat and YSZ topcoat after TBC deposition. The as-deposited YSZ topcoat was tightly-adherent to the thin oxide scale grown on the $\sim 10 \mu \mathrm{m}$ thick bond coat during the pre-oxidation treatment. The Mo-70Al coating exhibited a two-phase microstructure with a Mo-rich phase embedded in the $\mathrm{Al}_{8} \mathrm{Mo}_{3}$ matrix. The Mo-rich phase was probably $\mathrm{AlMo}_{3}$, precipitated due to Al-depletion of the coating caused by interdiffusion and oxide formation during annealing and pre-oxidation. The oxide scale was assumed to consist of a mixture of aluminium borates. As found in a previous study, XRD measurements of Mo-9Si-8B specimens with $9.2 \mu \mathrm{m}$ thick Mo-70Al oxidation protective layers, which were exposed to air at $800^{\circ} \mathrm{C}$ and $1000^{\circ} \mathrm{C}$ for $20 \mathrm{~h}$, indicated the aluminium borates $\mathrm{AlBO}_{3}$ and $\mathrm{Al}_{5} \mathrm{BO}_{9}$ in the thermally grown oxide scales [35]. Furthermore, the aluminium borate $\mathrm{Al}_{4} \mathrm{~B}_{2} \mathrm{O}_{9}$ was observed in the outer oxide scale of a Mo-11.2Si-8.1B7.3 $\mathrm{Al}$ (at.\%) sample which was oxidised in air at $900^{\circ} \mathrm{C}$ for $24 \mathrm{~h} \mathrm{[36].}$

After exposure to air at $1000^{\circ} \mathrm{C}$ for 20 hours, the Mo-9Si-8B sample with Mo-70Al bond coat and YSZ topcoat exhibited severe oxidation around the unprotected suspension hole (Figure 2a). Such a severe oxidation was also observed on a similar sample with Mo-70Al coating but without ceramic topcoat [35]. On the latter sample, aluminium molybdate formed due to a reaction between aluminium borate and molybdenum trioxide resulting from oxidation of the bare substrate. As revealed by cross-sectional examination, this reaction product penetrated into the inter-columnar gaps of the EB-PVD YSZ topcoat in the region around the suspension hole (Figure 3a). In the filled gaps of the TBC, aluminium and molybdenum were detected by EDS. The Mo-70Al bond coat there was entirely oxidised and oxidation of the Mo-9Si-8B substrate occurred. Thick oxide layers formed and wide gaps were observed leading to 
spallation of the TBC (Figure 3a). Furthermore, EDS analysis of the oxides suggested a chemical reaction between silica and zirconia $\left(\mathrm{ZrSiO}_{4}\right.$ formation) as well as between Mo-, $\mathrm{Y}$-, Zr-oxides. Away from the suspension hole, however, the bond coat was largely still intact, albeit entirely oxidised at several areas (Figure 3b). A crevice was mostly observed between bond coat and YSZ topcoat. This delamination might be related to cross-section preparation. It has to be noted, however, that the coefficient of thermal expansion (CTE) of aluminium borate $\left((3-5) \times 10^{-6} \mathrm{~K}^{-1}[37]\right)$ is lower than that of alumina $\left((8-9.2) \times 10^{-6} \mathrm{~K}^{-1}[38]\right)$, causing higher thermal stresses in the system YSZ/aluminium borate in comparison to YSZ/alumina applied on Ni-based superalloys. However, the oxidation protection of the used $\mathrm{Al}_{8} \mathrm{Mo}_{3}$ coating is not clear due to interference with oxidation of the substrate material at uncoated areas around the suspension hole [35]. The thickness of the bond coat has probably to be increased to enhance the oxidation protection capability; and oxidation of the Mo-Si-B substrate resulting in the formation of volatile $\mathrm{MoO}_{3}$ has to be avoided by a perfectly protective coating. A $100 \mu \mathrm{m}$ thick $\mathrm{Al}_{8} \mathrm{Mo}_{3}$ coating with $\mathrm{Mo}_{5} \mathrm{SiB}_{2}$ diffusion barrier interlayer was expected to provide oxidation protection to Mo-Si-B alloys for more than $1000 \mathrm{~h}$ at $1300^{\circ} \mathrm{C}[39]$

For the TBC systems with YSZ topcoat and Mo-46Si-24B bond coat, neither significant oxidation nor chemical reaction were observed at areas around the suspension hole after exposure to air at $1000^{\circ} \mathrm{C}$ for $20 \mathrm{~h}$ (Figure $2 \mathrm{~b}$ ). The ceramic topcoat exhibited good adhesion to the formed oxide scale (Figure 4). The basket-weave structure visible in the lower part of the $\mathrm{TBC}$ was related to the twofold rotation of the samples over the EB-PVD source during deposition of the ceramic topcoat. Below the TGO, the remaining bond coat was observed. Its chemical composition measured by EDS analysis correlated to the $\mathrm{MoSi}_{2}$ phase. As reported in our previous paper on magnetron sputtered oxidation protection coatings for Mo-9Si-8B alloys, the TGO consisted of borosilicate [16]. In the latter study, an about $2 \mu \mathrm{m}$ thick 
intermediate $\mathrm{Mo}_{5} \mathrm{SiB}_{2}$ barrier layer was applied between the $\sim 5 \mu \mathrm{m}$ thick Mo-45Si-25B coating and the Mo-Si-B substrate (no ceramic topcoat was deposited). The oxidation protective coating, being amorphous in the as-sputtered condition, transformed into a crystalline microstructure with the $\mathrm{MoSi}_{2}$ and $\mathrm{MoB}$ phases during the annealing treatment. The annealed Mo-45Si-25B coating comprised an outer porous columnar layer and an inner dense $\mathrm{MoSi}_{2}$ layer. During exposure to air at $800^{\circ} \mathrm{C}$ and $1000^{\circ} \mathrm{C}$ for up to $100 \mathrm{~h}$, a protective borosilicate scale formed. The outer columnar region of the coating was entirely oxidised [16]. In the present work, no intermediate diffusion barrier layer was used for TBC systems with YSZ topcoat (development and manufacture of $\mathrm{Mo}_{5} \mathrm{SiB}_{2}$ interlayers by magnetron sputtering were carried out at a later date and, after optimisation of the process parameters, diffusion barriers were applied for GZO TBCs). Therefore, an accelerated degradation of the bond coat by interdiffusion happened. Cross-sectional analysis revealed that more than half of the bond coat with an initial thickness of approximately $5 \mu \mathrm{m}$ was consumed after $20 \mathrm{~h}$ of exposure at $1000^{\circ} \mathrm{C}$ due to oxide scale formation and diffusion of silicon into the substrate (Figure 4b). A chemical reaction between YSZ and TGO was not observed after this short high temperature exposure. The YSZ topcoat did not spall off after removal of the coated sample from the furnace. In the cross-section of this sample, however, crevices between topcoat and TGO were largely observed. These gaps might be related to cross-section preparation or to thermal stresses. CTE values for the different materials of the TBC system are: $(10-11) \times 10^{-6} \mathrm{~K}^{-1}$ for YSZ [40], $(3-4) \times 10^{-6} \mathrm{~K}^{-1}$ for borosilicate glasses [41-43], (8-10) $\times 10^{-6}$ $\mathrm{K}^{-1}$ for $\mathrm{MoSi}_{2}$ [44], and (5.8-6.7) $\times 10^{-6} \mathrm{~K}^{-1}$ for Mo-Si-B alloys [45]. With increasing thickness of the borosilicate scale, thermal stresses will be an issue due to the large mismatch in CTE between borosilicate and YSZ. Glass additives might be useful to enhance the CTE of the TGO and, thus, to mitigate thermal stresses. 


\subsection{Gadolinium zirconate topcoat}

Figure 5a shows the TBC system composed of GZO topcoat and Mo-46Si-24B bond coat after $20 \mathrm{~h}$ of exposure to air at $1000^{\circ} \mathrm{C}$. In contrast to the TBC system with YSZ topcoat, an intermediate $\mathrm{Mo}_{5} \mathrm{SiB}_{2}$ (T2) diffusion barrier layer was applied to mitigate the degradation of the oxidation protective coating by interdiffusion. The bond coat consisted of an outer loose columnar and an inner dense $\mathrm{MoSi}_{2}$ layer, as reported previously [16]. Below the T2 diffusion barrier, areas of $\mathrm{MoSi}_{2}$ were found formed by silicon diffusing through cracks in the T2 interlayer into the Mo-rich substrate. The roughness of the outer columnar region of the bond coat, occurring after the vacuum annealing treatment [16], impaired the initial growth of the GZO topcoat in the root area and pores very often formed above the depressions. However, during the continuous deposition process, the topcoat developed a columnar structure typically for EB-PVD TBCs. The corrugated root area was nearly pore-free, suggesting a chemical reaction between GZO and the oxide scale. Evidence of incompatibility of GZO with the TGO was also provided by cross-sectional examination of a Mo-Si-B sample with this $\mathrm{TBC}$ system which was exposed to air at $1000^{\circ} \mathrm{C}$ for $40 \mathrm{~h}$. An approximately $2 \mu \mathrm{m}$ thick dense zone was observed between the borosilicate scale and the GZO columns (Figure 5b). In this area, Mo and Si were detected by EDS analysis. Concentrations of about 5 at.\% were determined.

A chemical reaction also occurred in the outer region of the GZO topcoat near the suspension hole of the Mo-9Si-8B sample with Mo-46Si-24B bond coat. After $40 \mathrm{~h}$ of exposure to air at $1000^{\circ} \mathrm{C}$, this corroded region exhibited a layered structure (Figure 6a). EDS elemental mapping revealed Zr- and Mo-enriched layers with the chemical composition 20Zr-4Gd-6Mo$70 \mathrm{O}$ and $11 \mathrm{Zr}-8 \mathrm{Gd}-10 \mathrm{Mo}-71 \mathrm{O}$ (at.\%), respectively (Figure 6b). XRD pattern indicated the phases $\mathrm{Gd}_{2}\left(\mathrm{MoO}_{4}\right)_{3}, \mathrm{ZrO}_{2}, \mathrm{Gd}_{2} \mathrm{O}_{3}$ and $\mathrm{MoO}_{2}$ (Figure 7). The $\mathrm{Gd}_{2}\left(\mathrm{MoO}_{4}\right)_{3}$ phase was also confirmed by XRD analysis of powdered GZO scratched off from the area around the 
suspension hole. Therefore, the Mo-rich layers presumably consisted of $\mathrm{Gd}_{2}\left(\mathrm{MoO}_{4}\right)_{3}$, whereas the $\mathrm{Zr}$-rich layers might be composed of $\mathrm{ZrO}_{2}$ with additions of $\mathrm{Gd}_{2} \mathrm{O}_{3}$ and $\mathrm{MoO}_{2}$. The corrosion of the outer GZO region was likely associated with the oxidation of the substrate at the unprotected areas around the suspension hole resulting in the formation of volatile $\mathrm{MoO}_{3}$, which then reacted with GZO. A similar chemical reaction was observed on Mo-Si-B specimens with $\mathrm{Al}_{8} \mathrm{Mo}_{3}$ coatings at areas near the suspension hole, leading to the formation of $\mathrm{Al}_{2}\left(\mathrm{MoO}_{4}\right)_{3}[35]$

This hot corrosion phenomenon was observed for all TBC systems with GZO topcoat. It is illustrated in Figure 8 showing macrographs of a Mo-9Si-8B sample with T2 diffusion barrier and Mo-37Si-15B bond coat after TBC deposition and after exposure to air at $1000^{\circ} \mathrm{C}$ for 20 h. Whereas the GZO had a white appearance after deposition (Figure 8a), high temperature corrosion occurred around the suspension hole during exposure to air at $1000^{\circ} \mathrm{C}$ for $20 \mathrm{~h}$, discernible by the yellowish region (Figure $8 \mathrm{~b}$ ). Far away from the suspension hole, the GZO topcoat was intact. This was confirmed by cross-sectional examination showing deep corrosion attack in the outer part of the GZO topcoat close to the suspension hole (Figure 9a), whereas no corrosion occurred at farther areas (Figure 9b).

Figure 10 shows the Mo-37Si-15B bond coat deposited on the T2 diffusion barrier after exposure at $1000^{\circ} \mathrm{C}$ for $20 \mathrm{~h}$. The bond coat exhibited high porosity and a multi-phase microstructure containing the $\mathrm{MoSi}_{2}, \mathrm{Mo}_{5} \mathrm{Si}_{3}$ and $\mathrm{MoB}$ phases, as identified by XRD measurements of similar coatings after vacuum annealing [16,35]. A thin borosilicate scale grew on the bond coat. The GZO topcoat revealed excellent adhesion to this TGO. Again, molybdenum ( $\sim 6$ at.\%) and silicon ( $\sim 3$ at. $\%)$ were detected in the root area of the TBC, but the reaction zone between GZO and TGO appeared to be narrow. 
Similar results were obtained for the TBC system with GZO topcoat, Mo-47Si-24Al bond coat and T2 diffusion barrier. Again, the surface region of the GZO topcoat suffered substantial corrosion attack during high temperature exposure. As shown in Figure 11, the GZO topcoat was well adherent to the oxide scale grown on the bond coat after $100 \mathrm{~h}$ of exposure to air at $1000^{\circ} \mathrm{C}$. The $\mathrm{TGO}$ was probably composed of silica and mullite-like inclusions. In a previous study, $\mathrm{SiO}_{2}$ and a mullite-like phase $\left(\mathrm{Al}_{2} \mathrm{SiO}_{5}\right)$ were identified by XRD measurements of a Mo-9Si-8B sample with Mo-48Si-24Al coating which was exposed to air at $1000^{\circ} \mathrm{C}$ for $100 \mathrm{~h} \mathrm{[17].} \mathrm{The} \mathrm{coating,} \mathrm{consisting} \mathrm{of} \mathrm{C} 40-\mathrm{Mo}(\mathrm{Si}, \mathrm{Al})_{2}$ phase after vacuum annealing, transformed into the $\mathrm{MoSi}_{2}$ and $\mathrm{Mo}_{5} \mathrm{Si}_{3}$ phases due to consumption of $\mathrm{Al}$ and $\mathrm{Si}$ by oxide formation. In the root area of the GZO topcoat up to 6 at.\% Mo were detected by EDS analysis, indicating diffusion of molybdenum into the TBC. However, the reaction between GZO and the TGO composed of silica and mullite-like oxides was less pronounced in comparison to the borosilicate scale formed on the Mo-46Si-24B bond coat (see Figure 5), suggesting a better compatibility of GZO with the former TGO.

When exposed to air at $1300^{\circ} \mathrm{C}$, the targeted service temperature for Mo-Si-B materials, the samples with GZO topcoat and various bond coats were heavily damaged and the TBC systems were entirely degraded after $10 \mathrm{~h}$ of exposure (Figure 12). Obviously, the increase of exposure temperature to $1300^{\circ} \mathrm{C}$ drastically aggravated the corrosion attack associated with the chemical reaction between $\mathrm{MoO}_{3}$ and $\mathrm{Gd}_{2} \mathrm{Zr}_{2} \mathrm{O}_{7}$ and led to rapid deterioration of the bond coat, resulting in severe destruction of the samples.

To operate at high temperatures up to $1300^{\circ} \mathrm{C}$, TBC systems on Mo-Si-B components require significantly thicker bond coats to provide long-term oxidation protection. Effective diffusion barrier have to be applied to retard the degradation of the bond coat by interdiffusion. Localised damage of the environmental protection leading to oxidation of bare substrate 
material with formation of volatile $\mathrm{MoO}_{3}$ is detrimental to the GZO topcoat due to strong reaction with molybdenum oxide. The chemical compatibility of GZO with TGO might be a further issue for long-term exposure. GZO was found to be sparsely compatible with alumina requiring an intermediate layer such as YSZ for TBC application [30]. A separating layer has probably to be applied also for bond coats forming silica/borosilicate scales.

\section{SUMMARY AND CONCLUSIONS}

Thermal barrier coatings of YSZ and GZO were deposited on Mo-9Si-8B samples using electron-beam physical vapour deposition. Magnetron sputtered 5 - $10 \mu \mathrm{m}$ thick bond coats were used forming protective oxide scales of aluminium borate, borosilicate and a mixture of silica and mullite-like oxides. After deposition the ceramic topcoats were tightly-adherent to the pre-oxidised bond coats.

The ceramic topcoats exhibited good adhesion to the oxide scales grown on the various bond coats during short-term exposure $(20-100 \mathrm{~h})$ at $1000^{\circ} \mathrm{C}$ in air. The chemical compatibility of GZO with a borosilicate scale might be an issue even at $1000^{\circ} \mathrm{C}$, which required more detailed studies.

During the high temperature exposure, substrate oxidation occurred at unprotected areas around the suspension hole of the samples, producing volatile $\mathrm{MoO}_{3}$. This molybdenum oxide reacted with the Al-70Mo bond coat and the GZO topcoat causing severe corrosion attack and damage of the samples, in particular at an increased temperature of $1300^{\circ} \mathrm{C}$. Such a corrosion attack was not observed on the Mo-9Si-8B sample with YSZ topcoat and Mo-46Si-24B bond coat exposed to air at $1000^{\circ} \mathrm{C}$ for $20 \mathrm{~h}$. 
For long-term operation of these TBC systems, the thickness of the bond coats has to be increased significantly to provide oxidation protection to the Mo-Si-B substrate material. Localised degradation of the coatings, provoking the formation of volatile $\mathrm{MoO}_{3}$, has to be avoided to prevent hot corrosion damage.

\section{ACKNOWLEDGMENTS}

The authors would like to thank and Mr. J. Brien, Mr. D. Peters and Mr. A. Handwerk for manufacturing the bond coats and the ceramic topcoats as well as performing the annealing treatments. The supply of the Mo-Si-B substrate material by Plansee SE, Reutte, Austria, is gratefully acknowledged.

\section{REFERENCES}

1 J.H. Perepezko: 'The hotter the engine, the better', Science, 2009, 326, 1068-1069.

2 B.P. Bewlay, M.R. Jackson, J.-C. Zhao, P.R. Subramanian, M.G. Mendiratta and J.J. Lewandowski: 'Ultrahigh-temperature Nb-silicide-based composites', MRS Bull., 2003, 28, 646-563.

3 M.R. Middlemas and J.K. Cochran: 'The microstructural engineering of Mo-Si-B alloys produced by reaction synthesis', JOM, 2010, 62(10), 20-24.

4 J.H. Perepezko, R. Sakidja and K.S. Kumar: 'Mo-Si-B alloys for ultrahigh temperature applications', in 'Advanced structural materials', (ed. W.O. Soboyejo et al.), 437-473; 2007, Boca Raton, CRC Press.

5 B.P. Bewlay, M.R. Jackson, J.-C. Zhao and P.R. Subramanian: 'A review of veryhigh-temperature Nb-silicide-based composites', Metall. Mater. Trans. A, 2003, 34A, 2043-2052.

6 K.S. Chan: 'Niobium alloys and composites', in 'Advanced structural materials', (ed. W.O. Soboyejo et al.), 401-436; 2007, Boca Raton, CRC Press.

7 J.H. Perepezko and R. Sakidja: 'Oxidation-resistant coatings for ultra-hightemperature refractory Mo-based alloys', JOM, 2010, 62(10), 13-19.

8 J.A. Lemberg and R.O. Ritchie: 'Mo-Si-B alloys for ultrahigh-temperature structural applications', Adv. Mater., 2012, 24, 3445-3480.

9 M. Heilmaier, M. Krüger, H. Saage, J. Rösler, D. Mukherji, U. Glatzel, R. Völkl, R. Hüttner, G. Eggeler, C. Somsen, T. Depka, H.-J. Christ, B. Gorr and S. Burk: 'Metallic 
materials for structural applications beyond nickel-based superalloys', JOM, 2009, 61(7), 61-67.

10 M. Krüger, P. Jain, K.S. Kumar and M. Heilmaier: 'Correlation between microstructure and properties of fine grained $\mathrm{Mo}-\mathrm{Mo}_{3} \mathrm{Si}-\mathrm{Mo}_{5} \mathrm{SiB}_{2}$ alloys', Intermetallics, 2014, 48, 10-18.

11 D. Schliephake, M. Azim, K. von Klinski-Wetzel, B. Gorr, H.-J. Christ, H. Bei, E.P. George, and M. Heilmaier: 'High-temperature creep and oxidation behavior of Mo-SiB alloys with high Ti contents', Metall. Mater. Trans. A, 2014, 45A, 1102-1111.

12 S. Paswan, R. Mitra and S.K. Roy: 'Oxidation behavior of Mo-Si-B and Mo-Si-B-Al alloys in the temperature range of $700-1300^{\circ} \mathrm{C}$ ', Intermetallics, 2007, 15, 1217-1227.

13 J.H. Perepezko and R. Sakidja: 'Oxidation resistant coatings for ultrahigh temperature refractory Mo-base alloys', Adv. Eng. Mater., 2009, 11, 892-897.

14 R. Sakidja, J.S. Park, J. Hamann and J.H. Perepezko: 'Synthesis of oxidation resistant silicide coatings on Mo-Si-B alloys', Scripta Mater., 2005, 53, 723-728.

15 R. Sakidja, F. Rioult, J. Werner and J.H. Perepezko: 'Aluminum pack cementation of Mo-Si-B alloys', Scripta Mater., 2006, 55, 903-906.

16 A. Lange, R. Braun and M. Heilmaier: 'Oxidation behavior of magnetron sputtered double layer coatings containing molybdenum, silicon and boron', Intermetallics, 2014, 48, 19-27.

17 A. Lange, R. Braun and M. Heilmaier: 'Magnetron sputtered $\mathrm{Mo}\left(\mathrm{Si}_{\mathrm{x}}, \mathrm{Al}_{1-\mathrm{x}}\right)_{2}$ oxidation protection coatings for Mo-Si-B alloys', Oxid. Met., 2015, 84, 91-104.

18 S. Kim and J.H. Perepezko: 'Interdiffusion kinetics in the $\mathrm{Mo}_{5} \mathrm{SiB}_{2}\left(\mathrm{~T}_{2}\right)$ phase', $J$. Phase Equilib. Diffus., 2006, 27, 605-613.

19 M. Akinc, M.K. Meyer, M.J. Kramer, A.J. Thom, J.J. Huebsch and B. Cook: 'Borondoped molybdenum silicides for structural applications', Mater. Sci. Eng., 1999, A261, 16-23.

20 H. Yokota, T. Kudoh and T. Suzuki: 'Oxidation resistance of boronized $\mathrm{MoSi}_{2}$ ', Surf. Coat. Technol., 2003, 169-170, 171-173.

21 M.P. Brady, B.A. Pint, P.F. Tortorelli, I.G. Wright and R.J. Hanrahan: 'Hightemperature oxidation and corrosion of intermetallics', in 'Corrosion and environmental degradation', (ed. M. Schütze.), vol. II, 229-325; 2000, Weinheim, Wiley-VCH.

22 E.J. Opila, N.S. Jacobson, D.L. Myers and E.H. Copland, 'Predicting oxide stability in high-temperature water vapor', JOM, 2006, 58(1), 22-28.

23 K.N. Lee: 'Current status of environmental barrier coatings for Si-based ceramics', Surf. Coat. Technol, 2000, 133-134, 1-7.

24 K.N. Lee, D.S. Fox and N.P. Bansal: 'Rare earth silicate environmental barrier coatings for $\mathrm{SiC} / \mathrm{SiC}$ composites and $\mathrm{Si}_{3} \mathrm{~N}_{4}$ ceramics', J. Eur. Ceram. Soc., 2005, 25, 1705-1715.

25 N.P. Padture, M. Gell and E.H. Jordan: 'Thermal barrier coatings for gas turbine engine applications', Science, 2002, 296, 280-284.

26 D.R. Clarke and S.R. Phillpot: 'Thermal barrier coating materials', Mater Today, 2005, 8, 22-29.

27 R. Vassen, X. Cao, F. Tietz, D. Basu and D. Stöver: 'Zirconates as new materials for thermal barrier coatings', J. Am. Ceram. Soc., 2000, 83, 2023-2028.

28 R. Darolia: 'Thermal barrier coatings technology: critical review, progress update, remaining challenges and prospects', Int. Mater. Rev., 2013, 58, 315-348.

29 R.M. Leckie, S. Krämer, M. Rühle and C.G. Levi: 'Thermochemical compatibility between alumina and $\mathrm{ZrO}_{2}-\mathrm{GdO}_{3 / 2}$ thermal barrier coatings', Acta Mater., 2005, 53, 3281-3292. 
30 V. Viswanathan, G. Dwivedi and S. Sampath: 'Multilayer, multimaterial thermal barrier coating systems: design, synthesis, and performance assessment, J. Am. Ceram. Soc., 2015, 98, 1769-1777.

31 R. Braun, A. Lange, U. Schulz, L. Portebois, S. Mathieu, M. Vilasi and S. Drawin: 'Environmental/thermal barrier coating systems deposited on $\mathrm{Nb} / \mathrm{Nb}_{5} \mathrm{Si}_{3}$ based alloy', Mater. High Temp., 2015, 32, 50-56.

32 R. Braun, A. Lange, U. Schulz, L. Portebois, S. Mathieu, M. Vilasi and S. Drawin: 'Lifetime of environmental/thermal barrier coatings deposited on a niobium silicide composite with boron containing $\mathrm{M}_{7} \mathrm{Si}_{6}$-based bond coat', Mater. Corros., 2016, 67, 1252-1260.

33 J.E. Jackson, A.N. Lasseigne-Jackson, T. Koenig, D.L. Olson and B. Mishra: 'Development of graded-architecture mullite thermal barrier coating on Mo-Si-B turbine materials', Proceedings of ASME Turbo Expo 2007: Power for Land, Sea and Air, , vol. 5, May 14-17, 2007, Montreal, Canada, Paper No. GT2007-27940, 137-146.

34 J.E. Jackson, D.L. Olson, B. Mishra and A.N. Lasseigne-Jackson: 'Deposition and characterization of Al-Si metallic precursor on Mo-Si-B turbine materials', Int. J. Hydrogen Energy, 2007,32, 3789-3796.

35 A. Lange and R. Braun: 'Magnetron-sputtered oxidation protection coatings for MoSi-B alloys', Corros. Sci., 2014, 84, 74-84.

36 J. Das, B. Roy, N.K. Kumar and R. Mitra: 'High temperature oxidation response of Al/Ce doped Mo-Si-B composites', Intermetallics, 2017, 83, 101-109.

37 S.P. Ray: 'Preparation and characterization of aluminum borate', J. Am. Ceram. Soc., 1992, 75, 2605-2609.

38 S. Bose: 'High temperature coatings', 2007, Elsevier Inc., Amsterdam, p.280.

39 F. Rioult, N. Sekido, R. Sakidja and J.H. Perepezko: 'Aluminum pack cementation on Mo-Si-B alloys: kinetics and lifetime prediction', J. Electrochem. Soc., 2007, 154, C692-C701.

40 D. Stöver, G. Pracht, H. Lehmann, M. Dietrich, J.-E. Döring and R. Vaßen: 'New material concepts for the next generation of plasma-sprayed thermal barrier coatings, J. Therm. Spray Technol., 2004, 13, 76-83.

41 A. Elkind, M. Barsoum and P. Kangutkar: 'Thermal expansion of silicon carbide monofilaments and silicon carbide-borosilicate composites, J. Am. Ceram. Soc., 1992, 75, 2871-2873.

42 A.R. Boccaccini, B.J.C. Thomas, G. Brusatin and P. Colombo: 'Mechanical and electrical properties of hot-pressed borosilicate glass matrix composites containing multi-wall carbon nanotubes', J. Mater. Sci., 2007, 42, 2030-2036.

43 O. Peitl and E.D. Zanotto: 'Thermal shock properties of chemically toughened borosilicate glass', J. Non-Cryst. Solids, 1999, 247, 39-49.

44 H.L. Zhao, M.J. Kramer and M. Akinc: 'Thermal expansion behavior of intermetallic compounds in the Mo-Si-B system', Intermetallics, 2004, 12, 493-498.

45 D.M. Dimiduk and J.H. Perepezko: 'Mo-Si-B alloys: developing a revolutionary turbine-engine material', MRS Bull., 2003, 28, 639-645. 
Table 1: TBC systems applied on Mo-9Si-8B samples which were exposed to air at $1000^{\circ} \mathrm{C}$ and $1300^{\circ} \mathrm{C}$ for different time periods. For the bond coats, the chemical composition in at.\% and the phases evolved during vacuum annealing are given.

\begin{tabular}{cccccc}
\hline \multirow{2}{*}{ Topcoat } & \multicolumn{2}{c}{ Bond coat } & \multicolumn{2}{c}{ T2 } & \multicolumn{2}{c}{ Testing parameters } \\
& Composition/at.\% & Phases & interlayer & Temperature $/{ }^{\circ} \mathrm{C}$ & Time $/ \mathrm{h}$ \\
\hline YSZ & $\mathrm{Mo-70Al}$ & $\mathrm{Al}_{8} \mathrm{Mo}_{3}$ & no & 1000 & 20 \\
\hline YSZ & Mo-46Si-24B & $\mathrm{MoSi}_{2}, \mathrm{MoB}$ & no & 1000 & 20 \\
\hline GZO & Mo-46Si-24B & $\mathrm{MoSi}_{2}, \mathrm{MoB}$ & yes & 1000 & 20,40 \\
& & & & 1300 & 10 \\
\hline GZO & $\mathrm{Mo-37Si-15B}$ & $\mathrm{MoSi}_{2}, \mathrm{Mo}_{5} \mathrm{Si}_{3}, \mathrm{MoB}$ & yes & 1000 & 20 \\
\hline \multirow{2}{*}{$\mathrm{GZO}$} & $\mathrm{Mo-47Si-24Al}$ & $\mathrm{Mo}\left(\mathrm{Si}_{1} \mathrm{Al}\right)_{2}$ & yes & 1000 & 100 \\
& & & & 1300 & 10 \\
\hline
\end{tabular}




\section{Figure captions}

Figure 1: Scanning electron micrographs of a Mo-9Si-8B sample with Mo-70Al bond coat and YSZ topcoat after TBC deposition, showing (a) the TBC system and (b) the transition region between $\mathrm{TBC}$ and substrate

Figure 2: Macrographs of Mo-9Si-8B samples with (a) Mo-70Al and (b) Mo-46Si-24B bond coats and YSZ topcoat after exposure to air at $1000^{\circ} \mathrm{C}$ for $20 \mathrm{~h}$

Figure 3: Scanning electron micrographs of a Mo-9Si-8B sample with Mo-70Al bond coat and YSZ topcoat which was exposed to air at $1000^{\circ} \mathrm{C}$ for $20 \mathrm{~h}$, showing (a) the corroded TBC system near the suspension hole and (b) the transition region between TBC and substrate farther away from the suspension hole

Figure 4: Scanning electron micrographs of a Mo-9Si-8B sample with Mo-46Si-24B bond coat and YSZ topcoat which was exposed to air at $1000^{\circ} \mathrm{C}$ for $20 \mathrm{~h}$, showing (a) the TBC system and (b) the transition region between TBC and substrate

Figure 5: Scanning electron micrographs of Mo-9Si-8B samples with T2 barrier layer, Mo46Si-24B bond coat and GZO topcoat which were exposed to air at $1000^{\circ} \mathrm{C}$ for (a) $20 \mathrm{~h}(\mathrm{BSE}$ image) and (b) $40 \mathrm{~h}$ (SE image)

Figure 6: (a) Scanning electron micrograph and (b) EDS elemental mapping of the outer topcoat region of a Mo-9Si-8B sample with T2 barrier layer, Mo-46Si-24B bond coat and GZO topcoat which was exposed to air at $1000^{\circ} \mathrm{C}$ for $40 \mathrm{~h}$ 
Figure 7: XRD pattern of the outer corroded region of the GZO topcoat deposited on a Mo9Si-8B sample with T2 barrier layer and Mo-46Si-24B bond coat after exposure to air at $1000^{\circ} \mathrm{C}$ for $40 \mathrm{~h}$

Figure 8: Macrographs of a Mo-9Si-8B sample with T2 barrier layer, Mo-37Si-15B bond coat and GZO topcoat (a) after TBC deposition and (b) after exposure to air at $1000^{\circ} \mathrm{C}$ for $20 \mathrm{~h}$

Figure 9: Scanning electron micrographs of a Mo-9Si-8B sample with T2 barrier layer, Mo37Si-15B bond coat and GZO topcoat which was exposed to air at $1000^{\circ} \mathrm{C}$ for $20 \mathrm{~h}$, showing (a) hot corrosion attack in the outer part of TBC near the suspension hole and (b) intact TBC at areas farther away

Figure 10: Scanning electron micrograph of a Mo-9Si-8B sample with T2 barrier layer, Mo$37 \mathrm{Si}-15 \mathrm{~B}$ bond coat and GZO topcoat which was exposed to air at $1000^{\circ} \mathrm{C}$ for $20 \mathrm{~h}$

Figure 11: Scanning electron micrograph of a Mo-9Si-8B sample with T2 barrier layer, Mo47Si-24Al bond coat and GZO topcoat which was exposed to air at $1000^{\circ} \mathrm{C}$ for $100 \mathrm{~h}$

Figure 12: Macrograph of Mo-9Si-8B samples with T2 barrier layer and (a,b) Mo-46Si-24B and (c) Mo-47Si-24Al bond coats and GZO topcoat after exposure to air at $1300^{\circ} \mathrm{C}$ for $10 \mathrm{~h}$ 


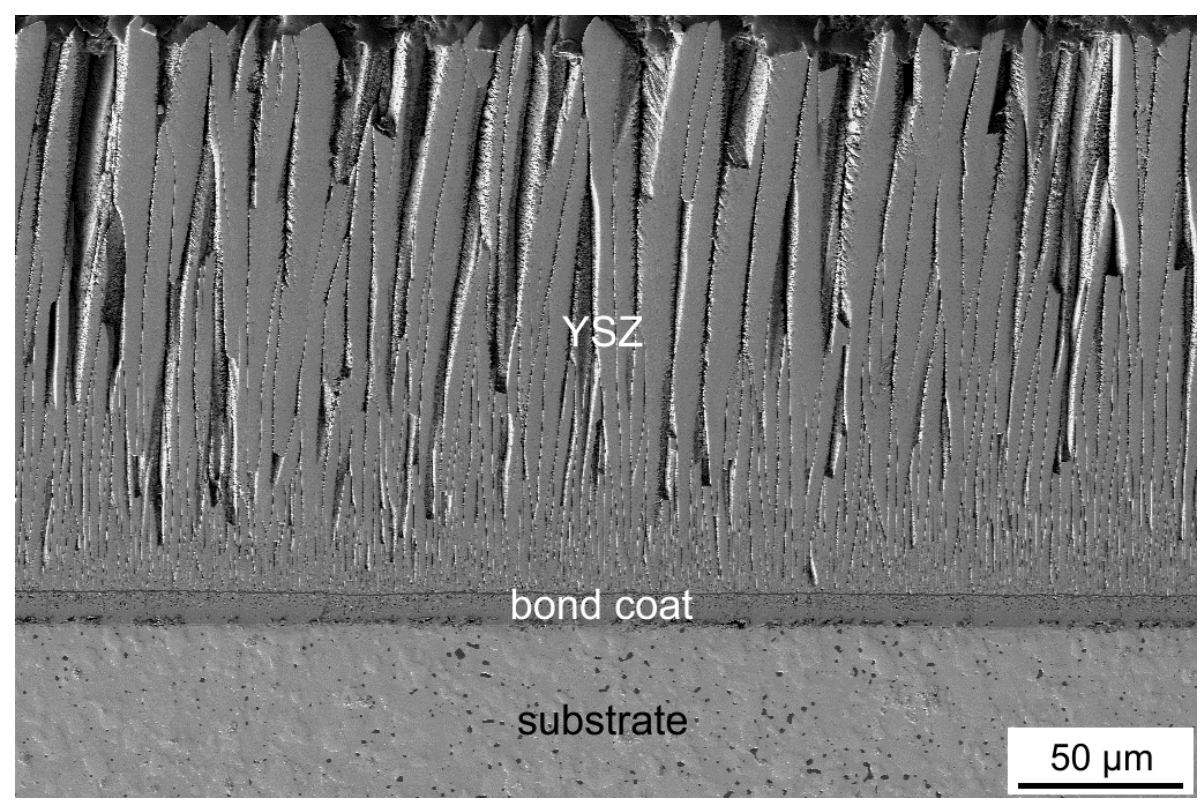

a

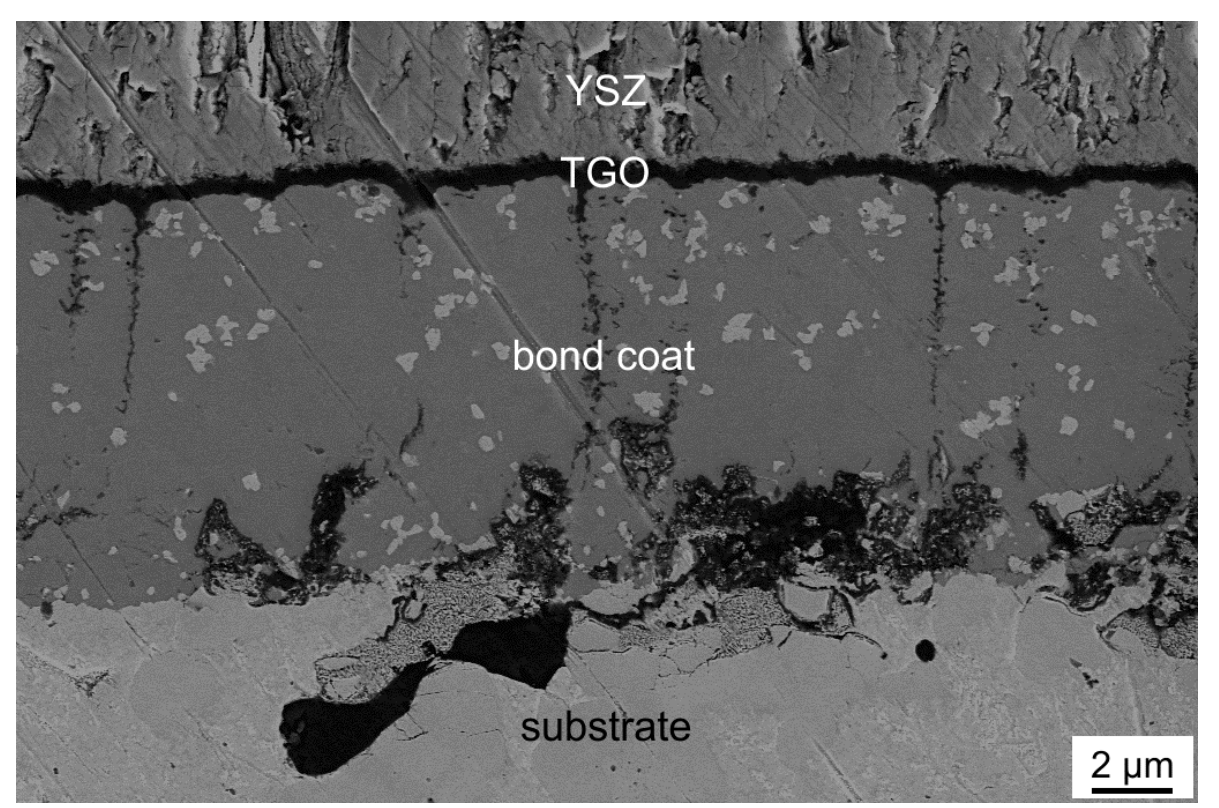

b

Figure 1: Scanning electron micrographs of a Mo-9Si-8B sample with Mo-70Al bond coat and YSZ topcoat after TBC deposition, showing (a) the TBC system and (b) the transition region between $T B C$ and substrate 


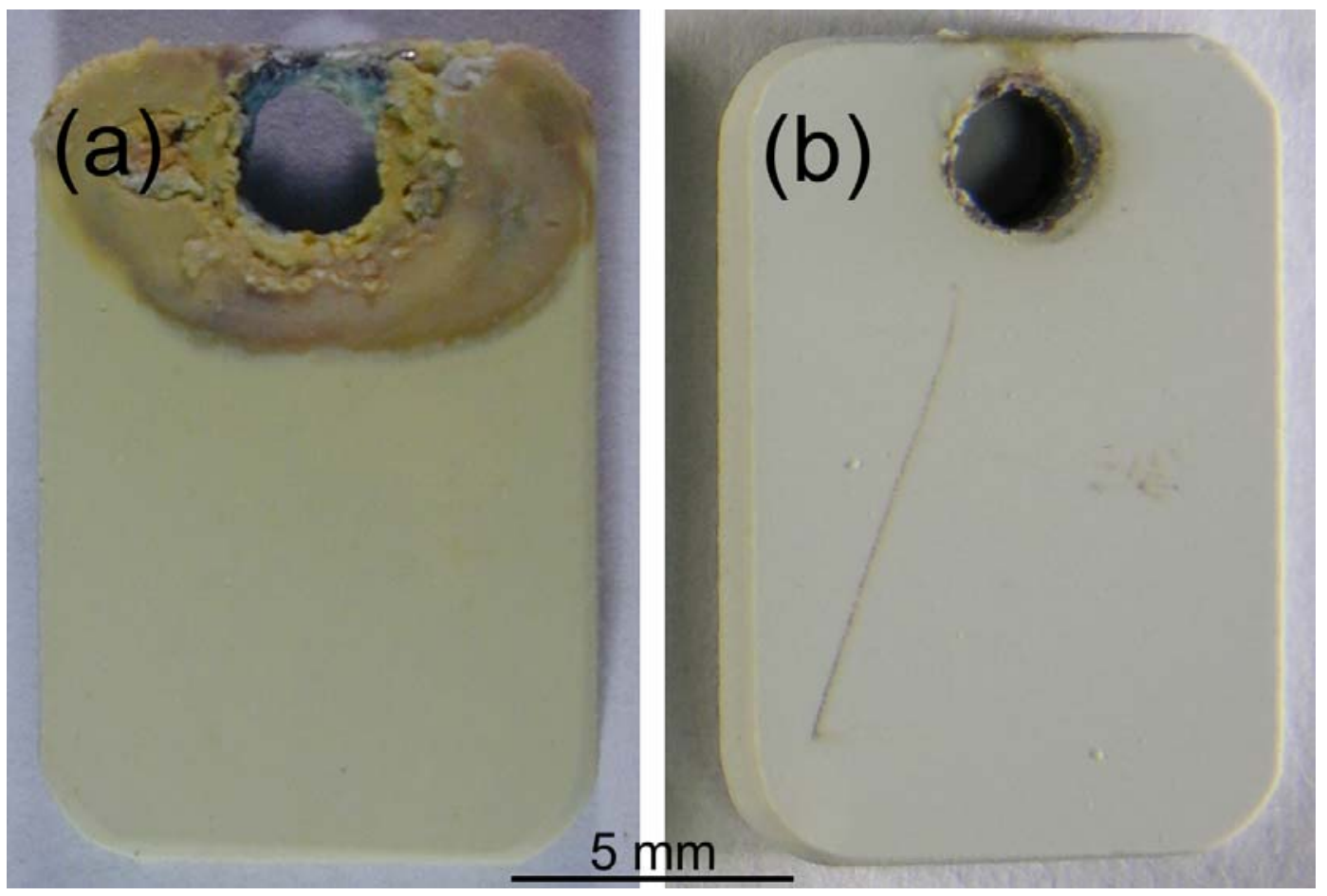

Figure 2: Macrographs of Mo-9Si-8B samples with (a) Mo-70Al and (b) Mo-46Si-24B bond coats and YSZ topcoat after exposure to air at $1000^{\circ} \mathrm{C}$ for $20 \mathrm{~h}$ 


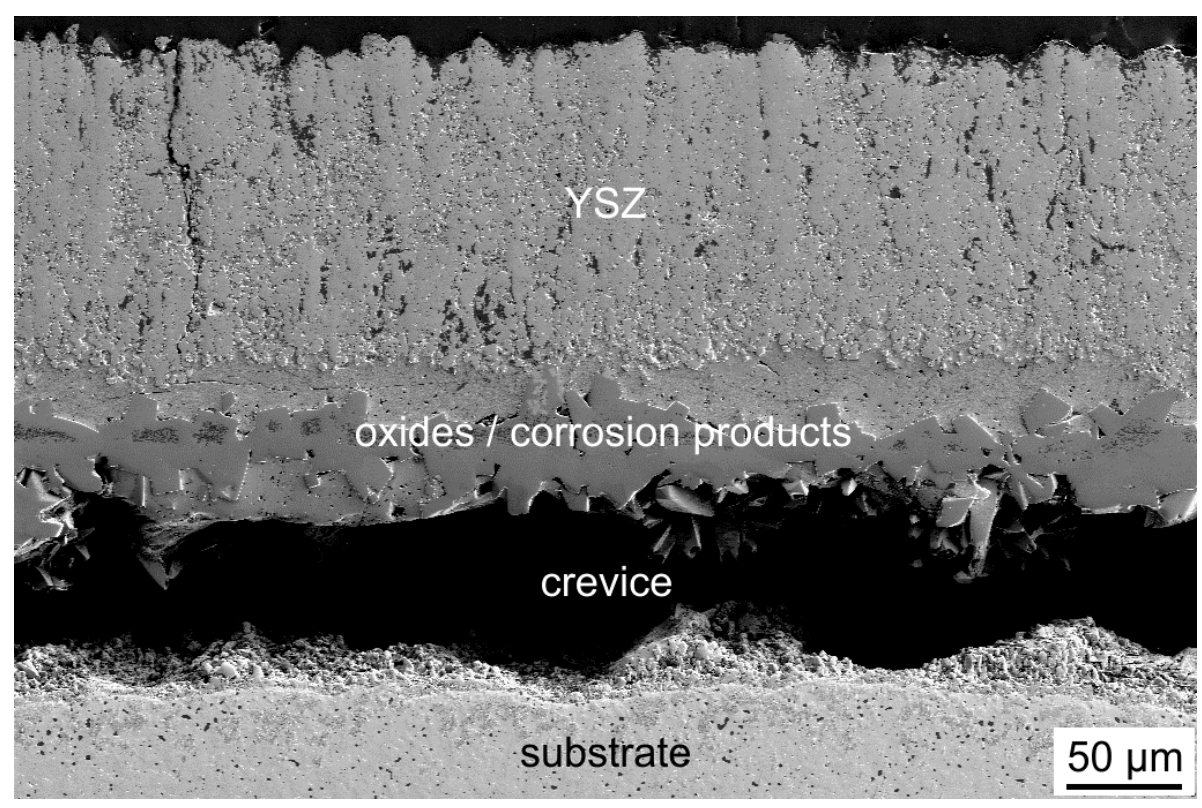

a

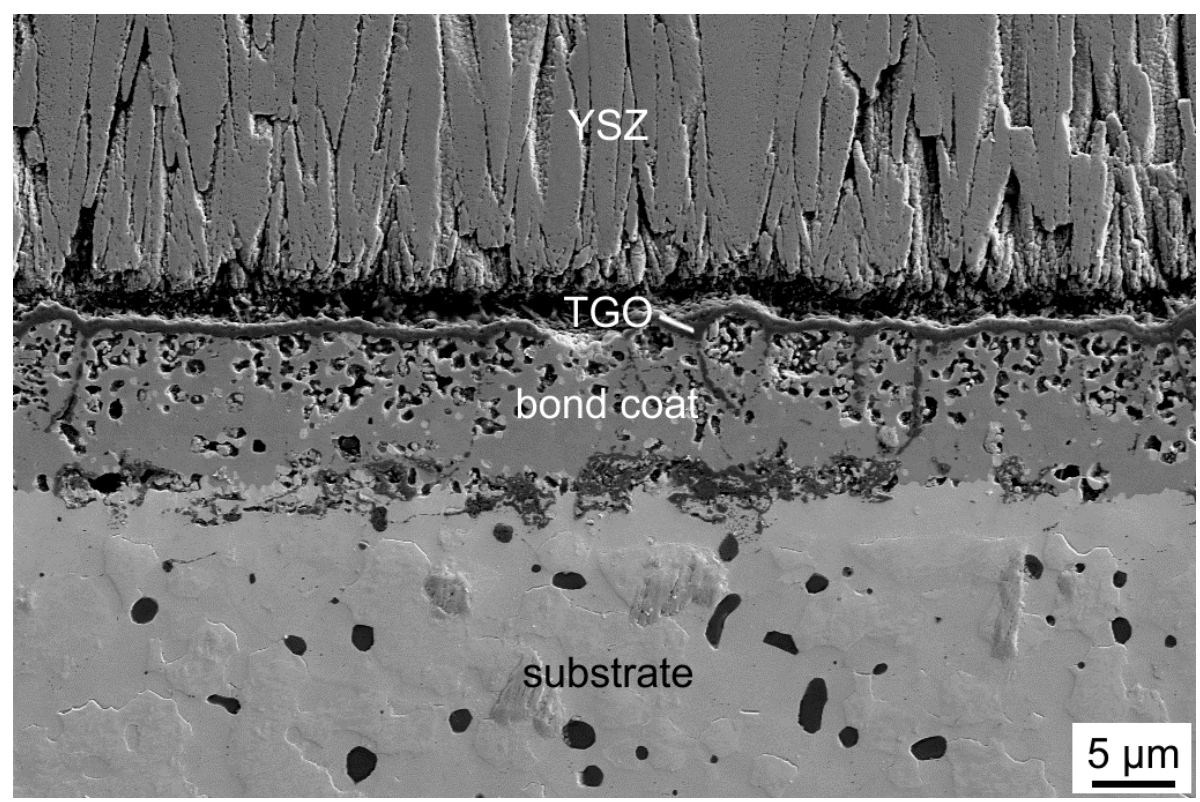

Figure 3: Scanning electron micrographs of a Mo-9Si-8B sample with Mo-70Al bond coat and YSZ topcoat which was exposed to air at $1000^{\circ} \mathrm{C}$ for $20 \mathrm{~h}$, showing (a) the corroded TBC system near the suspension hole and (b) the transition region between TBC and substrate farther away from the suspension hole 

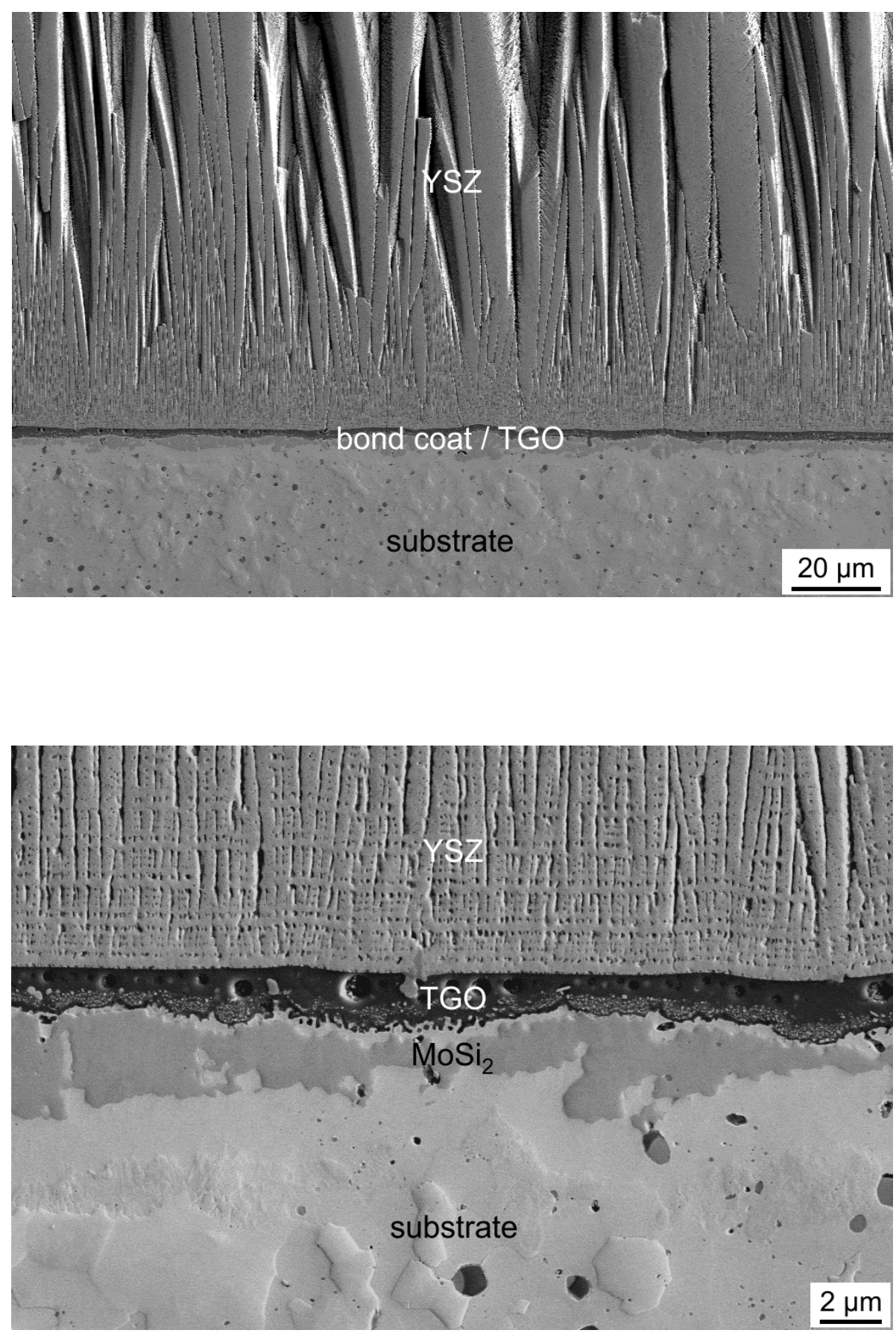

a

Figure 4: Scanning electron micrographs of a Mo-9Si-8B sample with Mo-46Si-24B bond coat and YSZ topcoat which was exposed to air at $1000^{\circ} \mathrm{C}$ for $20 \mathrm{~h}$, showing (a) the TBC system and (b) the transition region between $\mathrm{TBC}$ and substrate 


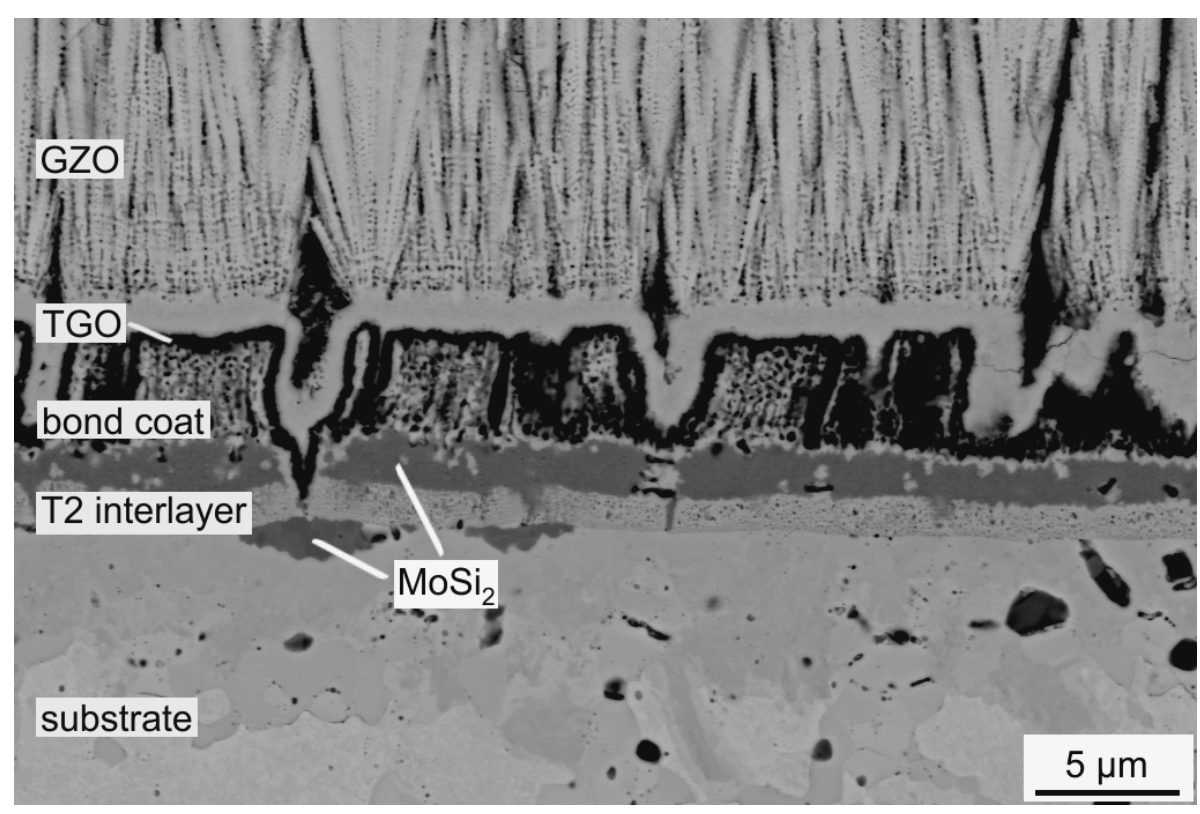

a
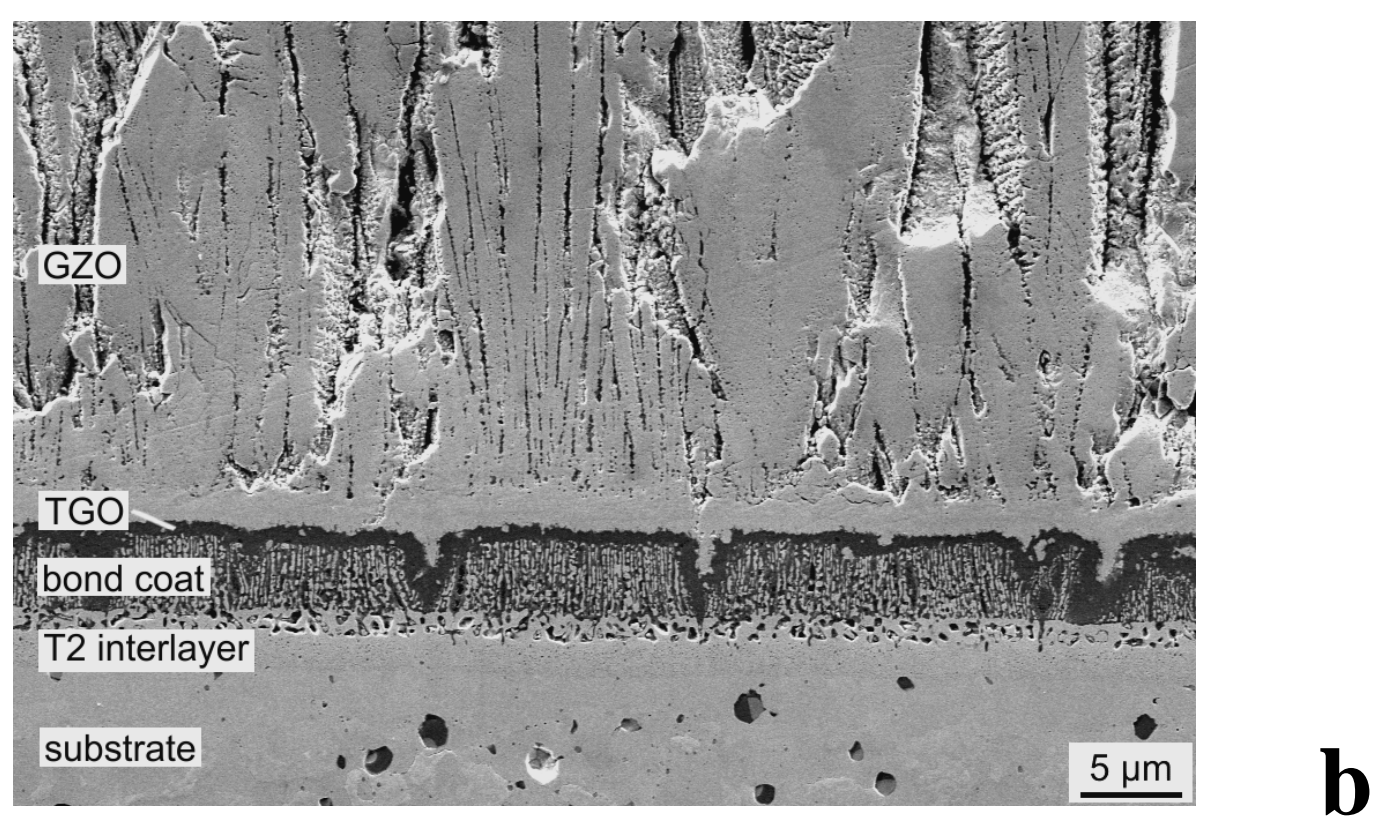

Figure 5: Scanning electron micrographs of Mo-9Si-8B samples with T2 barrier layer, Mo$46 \mathrm{Si}-24 \mathrm{~B}$ bond coat and GZO topcoat which were exposed to air at $1000^{\circ} \mathrm{C}$ for (a) $20 \mathrm{~h}$ (BSE image) and (b) $40 \mathrm{~h}$ (SE image) 


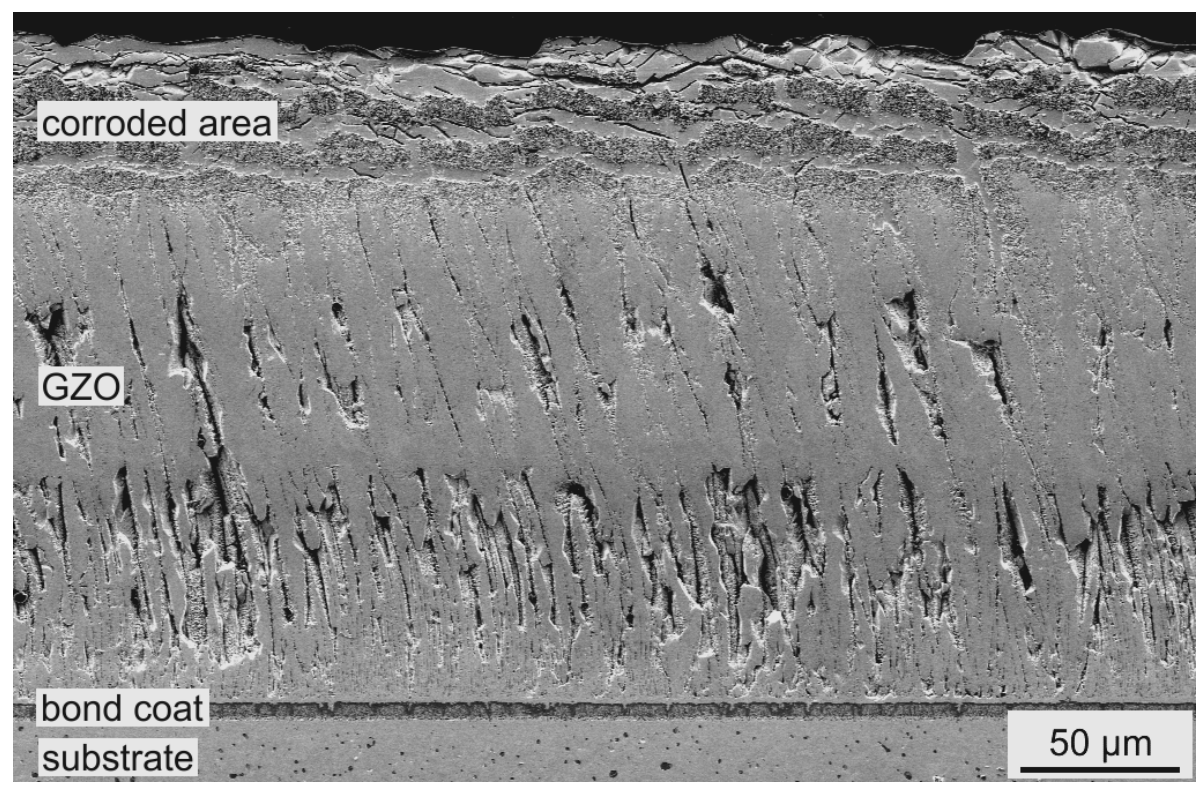

a
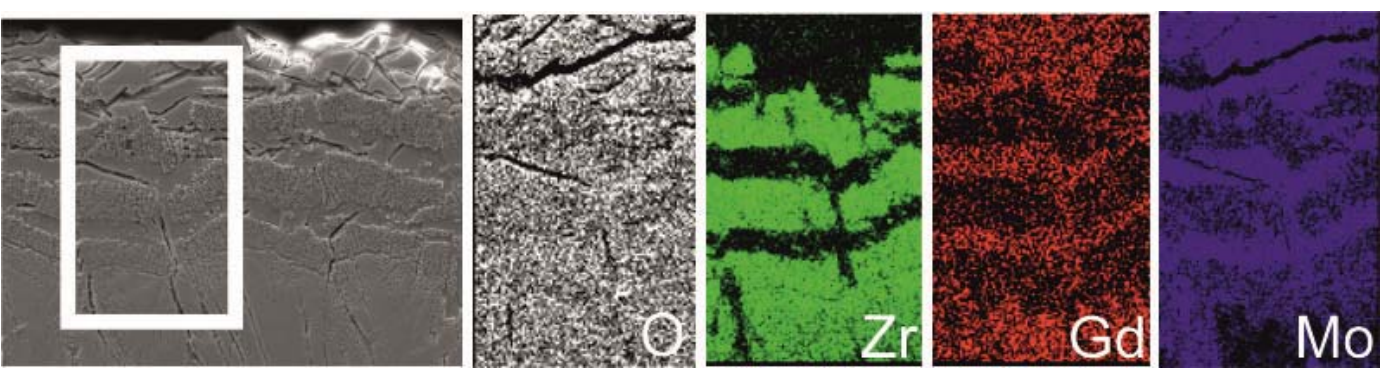

b

Figure 6: (a) Scanning electron micrograph and (b) EDS elemental mapping of the outer topcoat region of a Mo-9Si-8B sample with T2 barrier layer, Mo-46Si-24B bond coat and $\mathrm{GZO}$ topcoat which was exposed to air at $1000^{\circ} \mathrm{C}$ for $40 \mathrm{~h}$ 


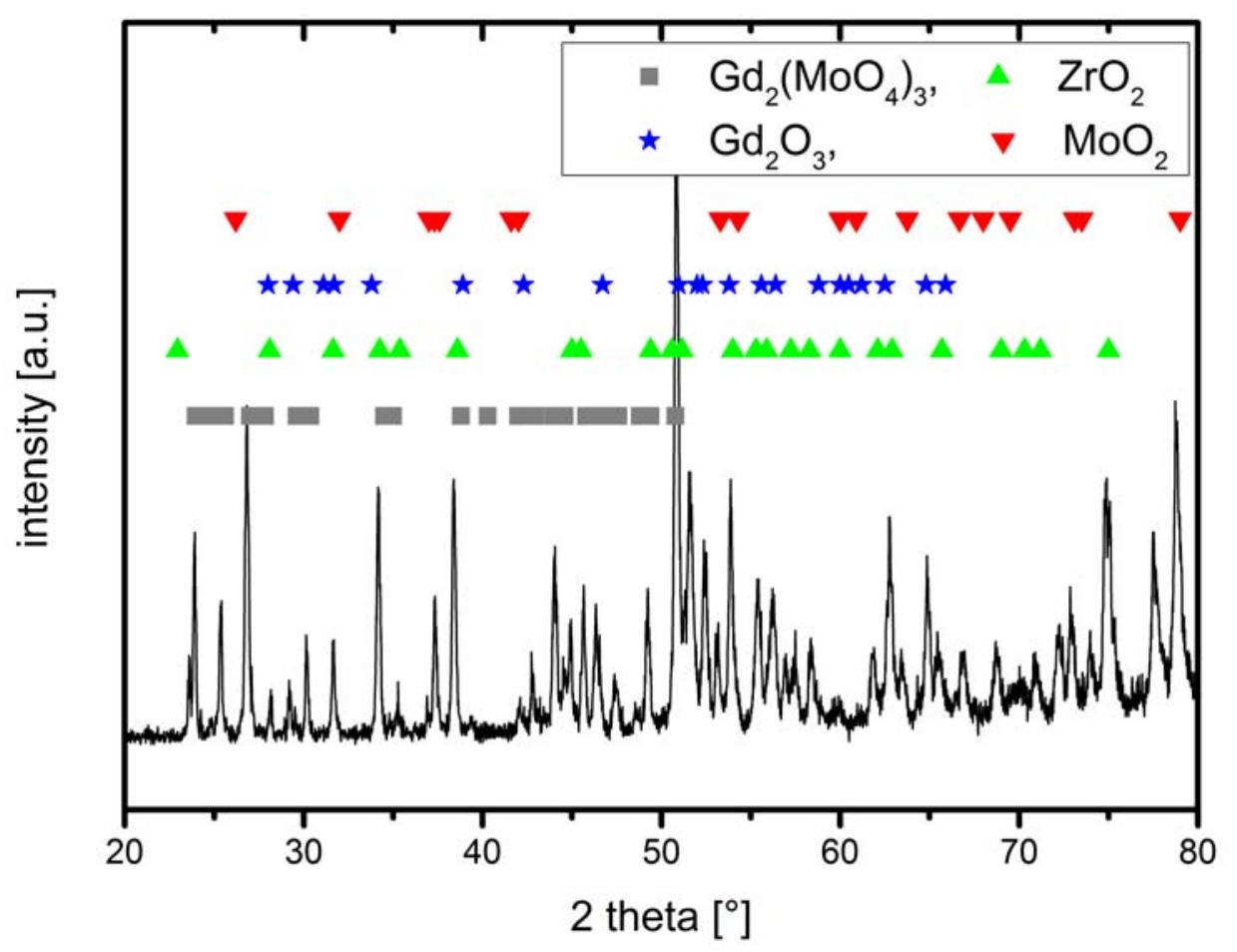

Figure 7: XRD pattern of the outer corroded region of the GZO topcoat deposited on a Mo9Si-8B sample with $\mathrm{T} 2$ barrier layer and Mo-46Si-24B bond coat after exposure to air at $1000^{\circ} \mathrm{C}$ for $40 \mathrm{~h}$ 


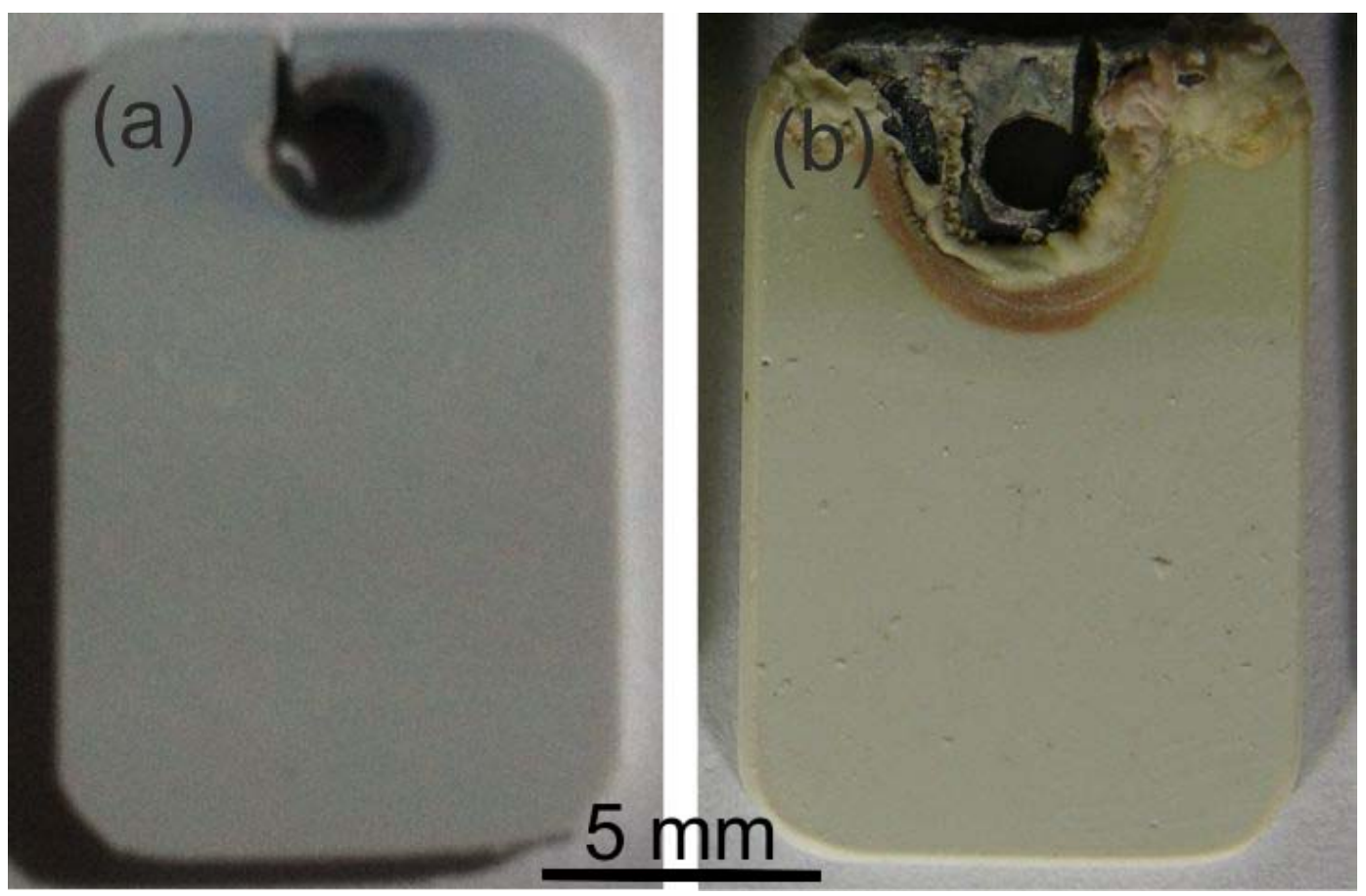

Figure 8: Macrographs of a Mo-9Si-8B sample with T2 barrier layer, Mo-37Si-15B bond coat and GZO topcoat (a) after TBC deposition and (b) after exposure to air at $1000^{\circ} \mathrm{C}$ for $20 \mathrm{~h}$ 


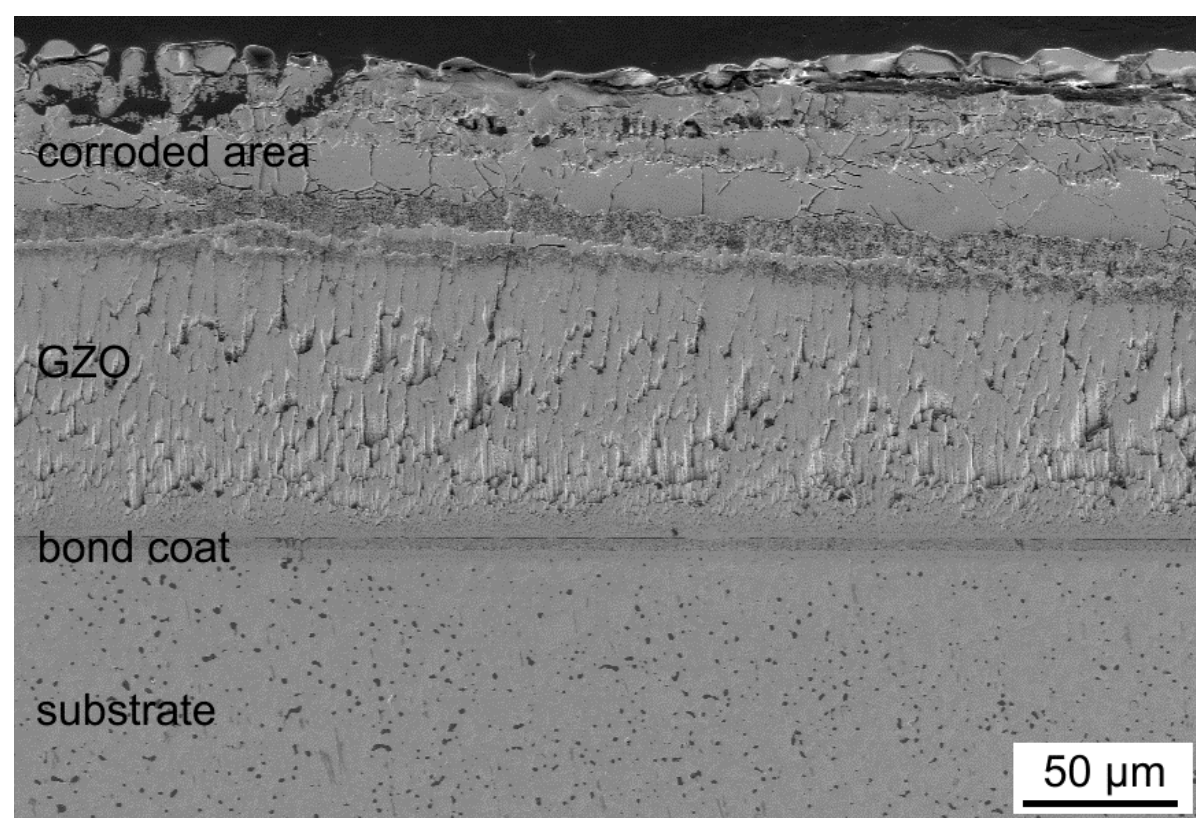

a

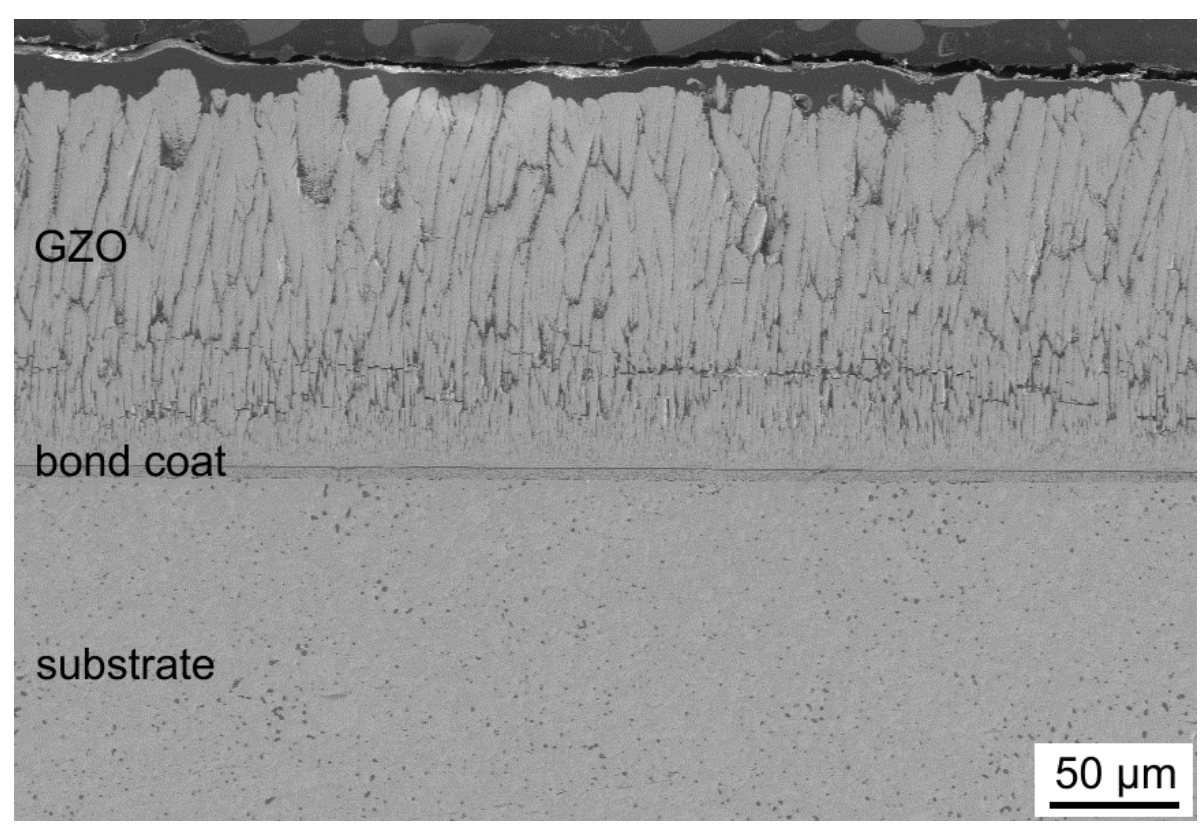

Figure 9: Scanning electron micrographs of a Mo-9Si-8B sample with T2 barrier layer, Mo$37 \mathrm{Si}-15 \mathrm{~B}$ bond coat and GZO topcoat which was exposed to air at $1000^{\circ} \mathrm{C}$ for $20 \mathrm{~h}$, showing (a) hot corrosion attack in the outer part of TBC near the suspension hole and (b) intact TBC at areas farther away 


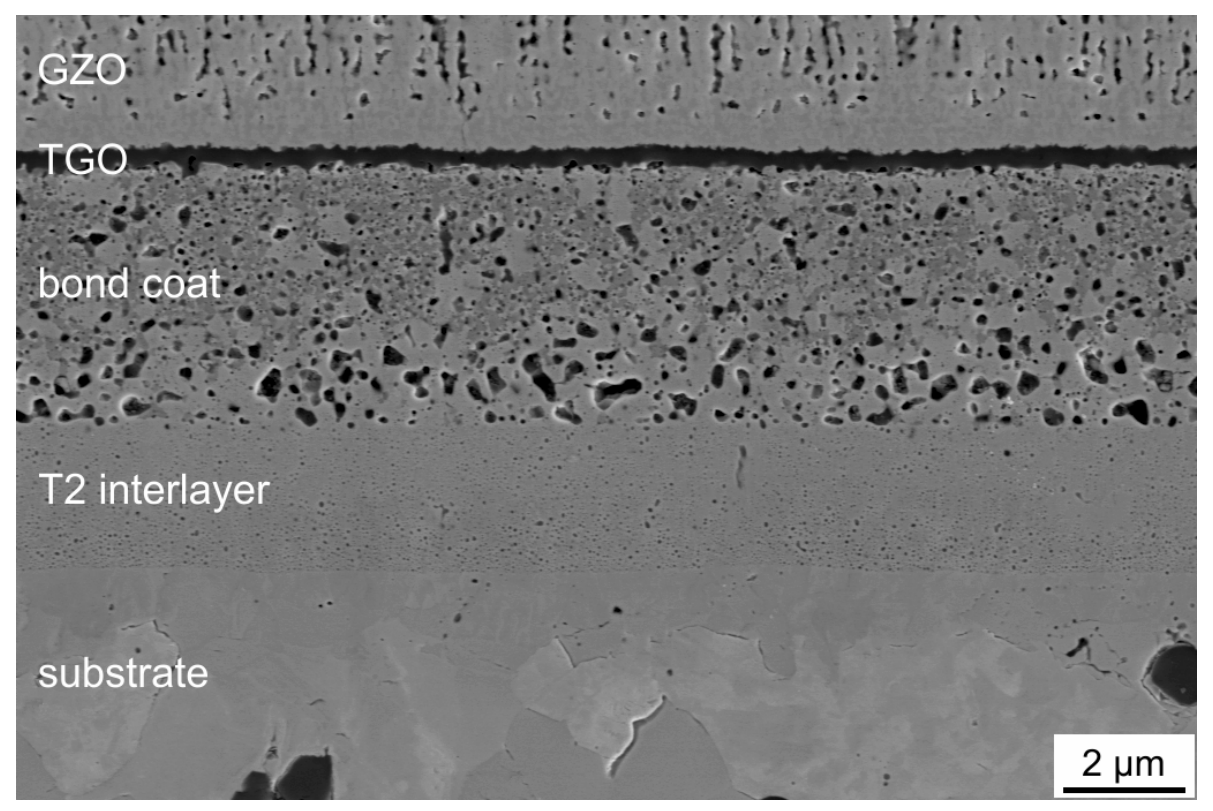

Figure 10: Scanning electron micrograph of a Mo-9Si-8B sample with T2 barrier layer, Mo$37 \mathrm{Si}-15 \mathrm{~B}$ bond coat and GZO topcoat which was exposed to air at $1000^{\circ} \mathrm{C}$ for $20 \mathrm{~h}$ 


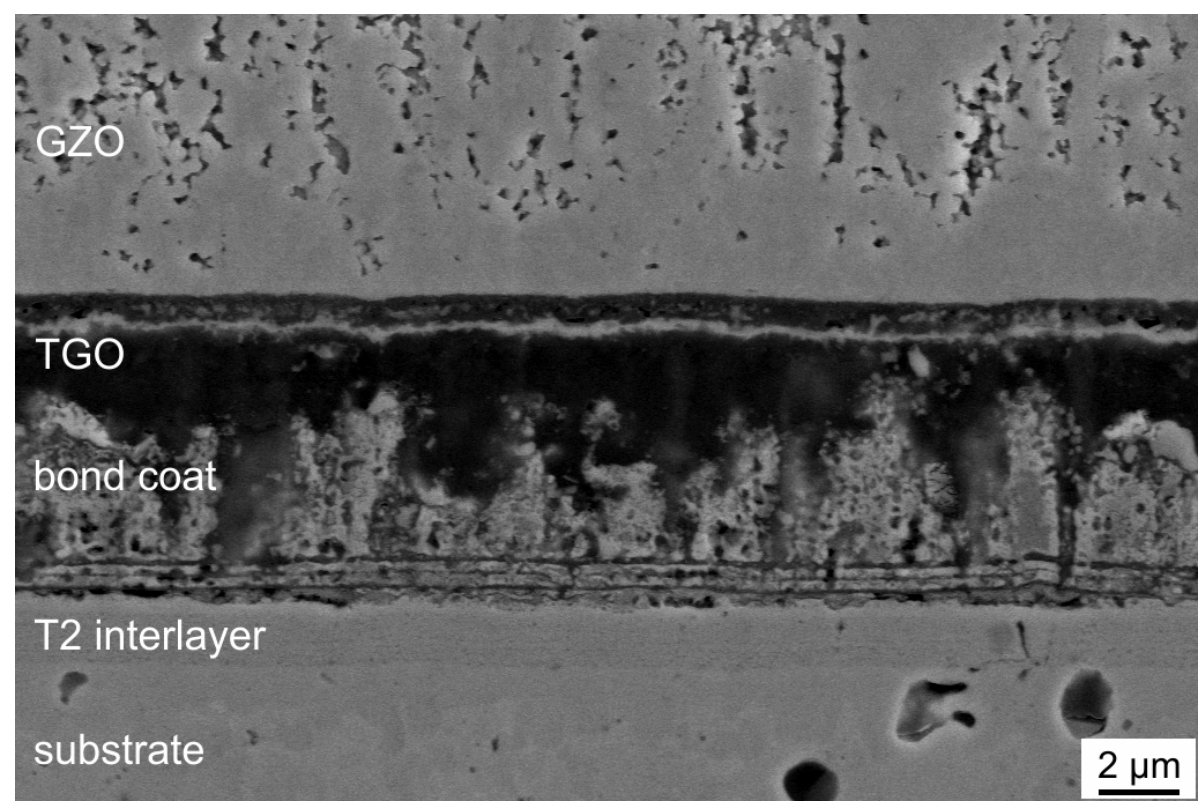

Figure 11: Scanning electron micrograph of a Mo-9Si-8B sample with T2 barrier layer, Mo$47 \mathrm{Si}-24 \mathrm{Al}$ bond coat and GZO topcoat which was exposed to air at $1000^{\circ} \mathrm{C}$ for $100 \mathrm{~h}$ 


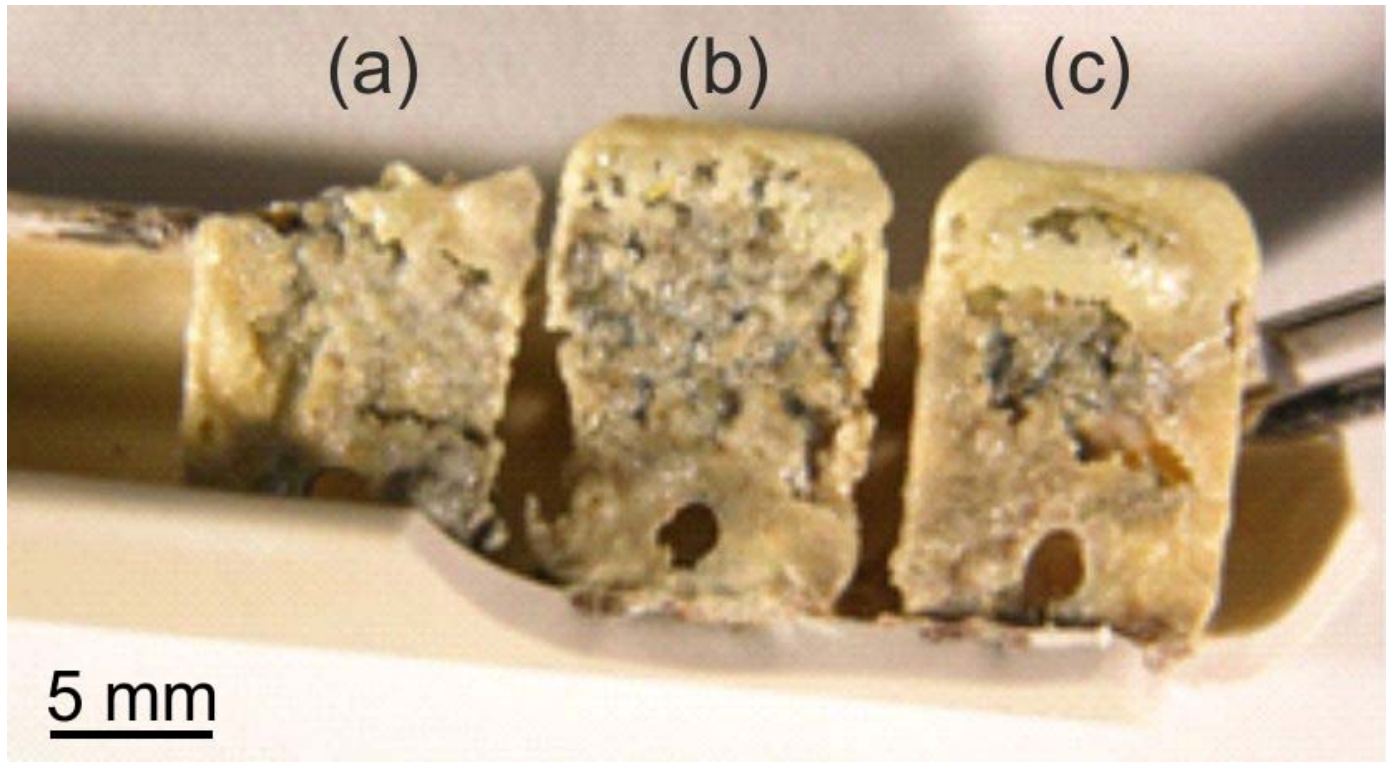

Figure 12: Macrograph of Mo-9Si-8B samples with T2 barrier layer and (a,b) Mo-46Si-24B and (c) Mo-47Si-24Al bond coats and GZO topcoat after exposure to air at $1300^{\circ} \mathrm{C}$ for $10 \mathrm{~h}$ 